\section{Defining a Rectangle under a Social and Practical Setting by Two Seventh Graders}

\author{
Fou-Lai Lin, Kai-Lin Yang, Taipei
}

\begin{abstract}
Regarding defining as a mathematical activity bridging informal to formal proof, two seventh graders will reinvent the definition of rectangles under a social and practical setting based on their informal argumentation. Their apprehensions of figures, implicit concepts/theorems and the cognitive architecture of defining are discussed in this paper.
\end{abstract}

Kurzreferat: In diesem Beitrag wird geschildert, wie zwei Siebtklässlerinnen auf der Grundlage informeller Argumentationen die Definition des Rechtecks entwickeln. Grundlage der Betrachtungen sind ihr Verständnis von Figuren, ihre impliziten Konzepte und Sätze sowie ihr kognitives Verständnis vom Definieren. Dabei wird Definieren als eine mathematische Aktivität angesehen, die informelles und formales Beweisen miteinander verbindet.

\section{ZDM-Classification: E40, C30}

\section{Introduction}

With reference to mathematical proof-problem solving, geometry has adopted to promote students' abilities of justification and proving for a long time in many countries. However, the teaching of geometrical proof appears to be a failure in almost all countries. Why cannot so many students succeed in proving? An analysis of teaching material indicates that there is too strong an emphasis on teaching the logical side of proof, while its social and practical importance in mathematical activity remains hidden (Balacheff, 1990). What causes mathematical proof to be one threshold of mathematics education, especially in geometry? Some researches (Vinner, 1991; Fishbein, 1993; Moore, 1994; Duval, 1998; Tall et al., 2001) have suggested major sources of the students' difficulties in doing (geometrical) proof, and definition is one of them. Definitions not only help form the concept image but every often have a crucial role in cognitive tasks (Vinner, 1991). Especially in geometry, a conflict between conceptual and figural constraints highlights the complexity of defining; however, it seems useful to find a problematic context within which the significance of a definition arises (Mariotti \& Fishbein, 1997). In general, defining is one of components of professional knowledge, and propositions of related knowledge are derived from definitions via proof or refutation among a community (Lacatos, 1976). For learning, Vinner (1991) considered that definitions in technical contexts violated students' thought habits in everyday life contexts, and suggested that mathematical concepts, images and definitions should be acquired in everyday life mode of concept formation but not in the technical modes and not only by introducing definitions.

In Taiwanese new mathematics curriculum for nine years compulsory education (1999), the competence guidelines about geometrical reasoning in grades 8-9 include local reasoning, understanding the meanings of definitions of some figures and relations and class inclusion. All of the competence guidelines are involved in the informal deduction level of the van Hiele model of geometric thought and postpone pure deductive proof. On the other hand, in view of mathematics as a human activity and the associated ideal of learning mathematics as a reinvention process (Freudenthal, 1973), it suggests that the protagonist to acquire knowledge is students, and students' informal knowledge and reasoning will be the focus of teaching and learning. Regarding defining as an educational problem and as a mathematical activity (Mariotti \& Fishbein, 1997), hence what kind of activities could initiate 7 th graders into defining and what obstacles to defining confront the students when they involve in inquiry activities are interesting themes of pedagogy and cognition. Is it possible that 7 th graders reinvent definitions if a meaningful context is set for defining? During the defining process, how do students shift from the particular to the general aspect of figures and vice versa, and what is students' cognitive scheme underling the plausibility of their thinking as elaborated by "What can this person be thinking so that his actions make sense from his perspective" (Thompson, 1982)? In other words, this paper intends to analyze how seventh graders potentially reinvent definitions of geometrical figures, and to reveal the cognitive structure of 7 th graders with respect to their informal argumentation towards the definitions of geometrical figures, which are also significant for bridging informal reasoning to formal reasoning (Duval, 2000; Hoyles \& Healy, 1999).

\section{Methodology}

This paper is part of a large study investigating the development of abilities of adolescent mathematical argument. The type of the large study is the conjunction of descriptive research and survey research. In the paper, we mainly utilize case studies to map out what and how grades 7 students conceptualize definitions and propositions of geometrical figures. Although case studies have restriction on generality and their interpretative objectivity is much suspected, they could give us an insight into the obscure thinking of students' argument about geometrical figures. Inhelder, Sinclair \& Bovet (1974) described it well:

\begin{abstract}
The very general theoretical problem concerns the existence and the explicative power of the factor of equilibration in cognitive learning. This mechanism is difficult to understand given transversal behaviors which do not take account of development expect by discontinuities of time. On the other hand, the method of inquiry that allows the tracing over a certain time period successive acquisitions of a child in a precise experimental context will allow, we hope, the gathering of clearer manifestations of this essentially dynamic mechanism.
\end{abstract}

Likewise, we intend to understand better the mechanism of developing definitions and propositions of geometrical 
figures with the method of inquiry in case studies.

With regard to interpretative objectivity, triangulation techniques are administered to enhance the validity of findings in the paper. The research team mainly constituted of 4 university professors, 2 schoolteachers and 4 postgraduates and regularly has a 3 -hour meeting about once weekly. The protocols coming from videos and tapes in the paper were first translated and coded by the postgraduates and triangulated by another two members of the group. The transcription had discussed by the team for almost 12 hours for the purpose of returning to what students originally expressed. With regard of inspecting the scope of restriction on generality, we will justify our findings with cross-section survey later, i.e., the results can be applied to design assessment tools in the future.

The qualitative data in the paper were gathered through two interviews. Color papers, straws, and scissors were offered in both interviews. The first in-depth interview was conducted for two hours in December 2000, and four tasks in the first interview were used to sketch what subjects' pre-conceptions of geometrical figures and their reasoning methods were. Besides the question in Fig. 1, there were another two task, similar to the question in Fig. 1, only changing the geometrical figures and one task about vertical angles. Three panels, two or three 7th graders and one postgraduate in each panel, were conducted in the first interview, and the function of postgraduates was just to keep argumentation from distraction and to confirm what students thought. At the end of the first interview, one of these subjects, S1, got the view that right angles were enough to determine a rectangle, and none of the other subjects mentioned any genetic definition of a rectangle. After three and half months, S1 was interviewed by her mathematics teacher, one member of the research team, to check if the genetic definition was still kept. It slightly took us by surprise that the result showed as if she had not experienced the first interview.

Following on the criticism of the first interview, an innovative and explorative task (Fig. 2) was developed for the purpose of clarifying conjectures and phenomena originating from the first interview, and it enabled to motivate students for carrying out defining process in a meaningful setting. To avoid that all properties of geometrical figures regarded as trivial truth by students hide the necessity and utility of defining it, the task (Fig. 2*) gave a condition that the payment was the less the better

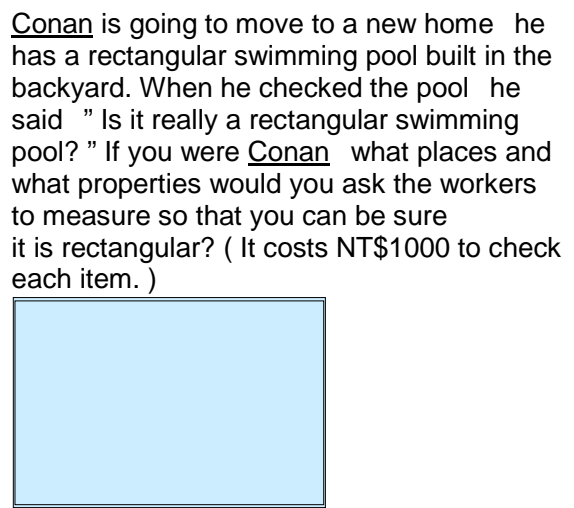

* Be sure, the payment is the less the better.

Fig. 2. The swimming pool task. after subjects had discussed some properties of rectangles. Mariotti and Fischbein (1997) had explored the great complexity of the defining process via the classification task and the unfolding/folding task. In contrast to their task, the swimming pool setting seems more explicit to lead students into the evolution of defining process in mathematics.

\begin{tabular}{l} 
There is a rectangle. \\
1. What is the relationship of the sides of this rectangle? \\
Explain your reasons. \\
\hline The relationship I find \\
2.What is the relationship of the angles of this rectangle? \\
Explain you reasons. \\
\hline The relationship I find \\
3. What else do you see from this rectangle? Explain your \\
reasons. \\
\hline What I see is \\
\hline
\end{tabular}

\section{Fig. 1. One of the first tasks.}

One panel, two 7th graders ( S1 and S2 ) and one researcher, was conducted in the second interview for about one and half hours, and the function of the interviewer was to diagnose and to intervene toward the definition of geometrical figures. The difference of the function of interviewers between first and second interviews was made to take account of learning mathematics as a social activity. The intervention in the second interview was based on three modes: provocative, invocative and validating (Kieren \& Pirie, 1992) for encouraging students to generate new ideas or to reason between properties by reducing costs, helping students to return to previous issues or sometimes with cognitive confliction strategies, and confirming subjects' thinking respectively. Besides each single mode intervention, two modes of interventions, provocative and invocative, were integrated for breaking the deadlock. The interviewer had changed the discussed figure from rectangles to squares and parallel lines when subjects were hampered by rectangles. Therefore, the importance of both social (intervention and peer discussions ) and practical (the swimming pool task) setting in mathematical activities, suggested by Balacheff (1990), was put into practice during the second interview.

\section{Theoretical Framework}

\subsection{Framework of Argumentation}

In attempts to map out the cognitive structure of grades 7 students with respect to their informal argumentation towards the definitions and propositions of geometrical figures, we first confronted a question that which framework was feasible for analyzing and interpreting students' informal argumentation. On the one hand argumentation is the process of arguing in a systematic or logical way, and on the other hand the content of argumentation is an essential factor influencing what and how students reason. In view of inferential ways and 
content, we adopted an alternative representation proposed by Tabachneck-Schijf and Simon (1996). They viewed a representation as a format for recording, storing and presenting information together with a set of operators for modifying the information. In this regard, both reasoning operators of argumentation and formats of content were meditated.

Previous research has focused on three reasoning modes : induction, deduction and invention ( abduction ) (Fischbein, 1996). Many rules under the deductive and inductive reasoning were investigated (e.g. Evans, Newstead \& Byrne, 1993; Holland et al., 1986), but it was still difficult to identify exactly what kinds of rules abduction ( invention ) executed. Nonetheless, we would students' argumentation activity, let us give them more precise explanations in Fig. 4. The framework would assist us in segmentalizing complex and extensive argumentation processes.

\subsection{Cognitive Theory for Action on Geometrical Figures} Because the data in this paper were directly related to reasoning in visualization, we would modify the four types of apprehensions of figures (Duval, 1995) described as follows to identify what subjects showed among those apprehensions with respect to their natural language and figural images.

(1) Perceptual Apprehension: Recognizing shapes and properties of figures in a plane or in depth.

\section{Fig. 3. Framework of argumentation.}

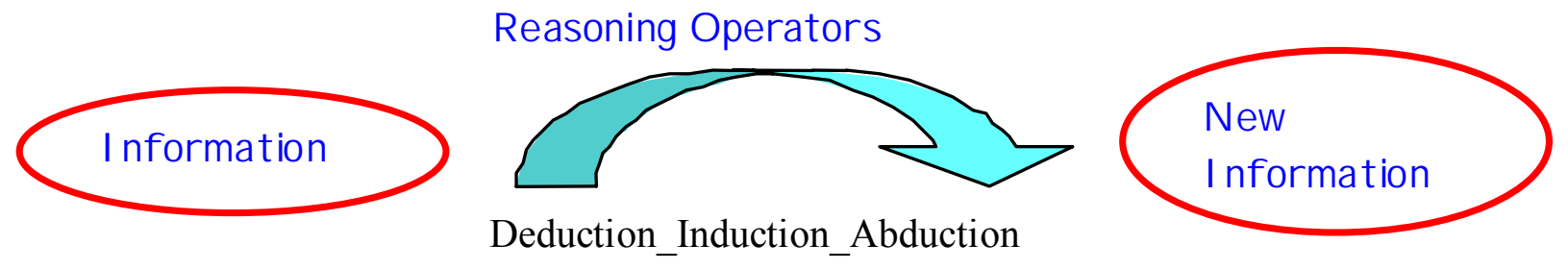

Fig. 4. Three categories of inferential operators.

\begin{tabular}{|l|l|l|l|l|}
\hline $\begin{array}{l}\text { Inferential } \\
\text { Operators }\end{array}$ & Information & $\begin{array}{l}\text { Inferential } \\
\text { Ways }\end{array}$ & $\begin{array}{l}\text { New } \\
\text { Information }\end{array}$ & Function \\
\hline Deduction & $\begin{array}{l}\text { given hypotheses and } \\
\text { required results }\end{array}$ & deductive laws & $\begin{array}{l}\text { refuted- } \\
\text { or proved- } \\
\text { proposition }\end{array}$ & $\begin{array}{l}\text { Verifying or validating a } \\
\text { conjecture. }\end{array}$ \\
\hline $\begin{array}{l}\text { possible patterns } \\
\text { Induction }\end{array}$ & specific examples & $\begin{array}{l}\text { analogizing } \\
\text { generalizing } \\
\text { conjecturing a pattern. }\end{array}$ & $\begin{array}{l}\text { Furnishing the subject with a } \\
\text { novel hypothesis to account for } \\
\text { surprising fact and motivating } \\
\text { orientations for future activity } \\
\text { (Cifarelli, 2000). }\end{array}$ \\
\hline
\end{tabular}

think about what kind of information, inferential ways and new information the three reasoning operators were related to and what function was in each operator. Which operators were specifically corresponding with geometrical figures when we focused formats of content on geometrical figures? On account of bearing the question in mind, we noticed that visual reasoning, transformation of figures or pictures, was also a powerful operator (Thurston , 1994; Davis, 1993) which was categorized into abduction in terms of generated information. Fig. 3 illustrates the above description of theoretical framework of argumentation. To avoid of misunderstanding the three inferential operators that we would employ to delineate
(2) Operative Apprehension: Transforming figures (the optic or the place way) or reorganizing configurations (the mereologic way)..

(3) Sequential Apprehension: Constructing a figure / describing its construction according to a specific order.

(4) Discursive Apprehension: Producing natural or theoretical discursive process basing on speech determination or deductive reasoning respectively for explanation or for proof.

Then we will extrapolate what were subjects' concepts/ theorems-in-action underlying schemes of competences developed by repeated conceptualization in dealing with situations (Vergnaud, 1998). The research could be 
regarded as an argumentation experiment of defining. On the grounds that the translation process, going from one mode of representation to another, was particular uses of symbolism promoting mathematical thinking (Janvier, 1987), Duval's (2000) cognitive architecture proposed to highlight that various coordinations between productive systems supports us a framework of perceptual categories to identify conversion and coordination within or between registers.

While Duval's cognitive architecture, an organization of several systems, put emphasis on multifunctional registers, Vergnaud's cognitive theory of practice put emphasis on the mechanism of conceptual field. Their perspectives on cognition seemed complementary for analyzing how subjects developed definitions and propositions of geometrical figures. Duval supported us a framework of perceptual categories to describe conversion and coordination between different registers, and Vergnaud supported us a framework of mental organization to explain cognitive mechanisms. Both of the two cognitive theories assisted us in conceptualizing how students conceptualized via reconstructing from observed actions.

\section{The Process of Defining Activities}

\subsection{The emergence of a Genetic Definition in the First Interview}

A genetic definition abstracted from some properties occurred only in the task and only in one member of a panel, S1, so the following process of argumentation of rectangles lasting about 30 minutes was focused on S1.

(1) Initially Proposed Properties: Firstly, the response to question (1) was that two pairs of opposite sides are equal because it (any two adjacent sides) must be perpendicular.

(2) Disordered Focus: While S2 queried and refuted S1's incomplete argument that if a pair of the opposite sides are parallel, the other pair of opposite sides are equal, $\mathrm{S} 1$ 's incomplete argument was based on assuming that the angles of the quadrangle are all right angles, which was vague at that time.

(3) Confirming Procedure: The researcher asked S1 why opposite sides are equal if the four angles are right angles, and S1 repeated that any two adjacent sides of a rectangle must be perpendicular, and then two pairs of opposite sides of the rectangle are equal.

(4) A Genetic Definition of Rectangles: At the end of the first argumentation, S1 got the view that right angles were enough to determine a rectangle and finally said that: I think there should be not rectangles which angles are not right angles, I dare say.

\subsection{Retracing the Genetic Definition}

Among the first argumentation, the research group challenged whether or not S1 had implicitly learned her genetic definition of rectangles. S1's genetic definition of rectangles was confirmed by her teacher three and half months later since the first interview. The result was that $\mathrm{S} 1$ had forgotten her genetic definition that right angles were enough to determine a rectangle. Why did only one subject develop a genetic definition, and why did her genetic definition disappear from her memory? The research team proposed two conceivable factors as follows.

(1) One factor came from outside of subjects. The factor was composed of two variables, the task and the intervention. S1 considered the relationship I found, the first question in the first task, was that two opposite sides were equal, and the reason was the four angles were right angles so the genetic definition of the four right angles might be accidentally molded by the task. Besides the task did not explicitly aim at production of definitions and just related to properties directly, the intervention was not set to guide subjects to achieve any explicit goal through the argumentation so there was no process of recapping or reviewing the result.

(2) The other factor came from the subject. The subject might not realize that the definition of a rectangle can be derived from what she had experienced.

In view of these reflections, we planed to modify the outside factor, which could be efficiently achievable. The swimming pool setting and the modes of intervention in the second interview were redesigned to enhance the evolution of defining rectangles and to respond to the needs of practical and social setting respectively.

\subsection{The Process of Reinventing Definitions of figures in the Second Interview}

The whole process in the second interview lasted one and half hours, and we just focused on the defining of rectangles and squares lasting about 40 minutes. The parts left aside included the conception of parallel and reasoning that the opposite angles and interior alternative angles are equal respectively. The following sequences (1)-(9) described their argumentation and interaction.

(1) Initially Proposed Properties of Rectangles: S1 proposed that two pairs of opposite sides were parallel, all angles were right angles and two pairs of opposite sides were equal. S2 proposed that all angles were right angles and two sides were larger than the others.

(2) Conjecturing: S2 thought that one must be sure that four angles were right angles. However, S1 thought one could be sure that a pair of opposite angles are right angles and that a pair of opposite sides are equal at first, and then changed into that one could be only sure that a pair of opposite angles are right angles.

\begin{tabular}{|c|c|c|}
\hline 96 & $\mathrm{~S} 2$ & $\begin{array}{l}\text { Something I want to measure and yours } \\
\text { are in common } \\
\text { angle } A \text {, the } \\
\text { length of these } \\
\text { two sides } \\
\text { (AB.AD)..... }\end{array}$ \\
\hline 97 & $\mathrm{R}$ & The length..... \\
\hline
\end{tabular}

\begin{tabular}{|c|c|l|}
\hline 126 & S1 & $\begin{array}{l}\text { Ok! Then this way, this way, Gia-Wen } \\
\text { needs 1.2.3.4.5, five thousands, ( 4 sides } \\
\text { and 1 angle). I do it this way. I need four } \\
\text { thousand (a pair of angles, a pair of sides). }\end{array}$ \\
\hline 127 & R & You four thousand... \\
\hline 128 & S1 & But it's not necessary that I'm right. \\
\hline
\end{tabular}




\begin{tabular}{|c|c|l|}
\hline 129 & S2 & But if you do it this way..... \\
\hline 130 & R & Can we save more money \\
\hline 131 & S2 & What about three thousand \\
\hline 132 & S1 & $\begin{array}{l}\text { I think angles must be measured, but if } \\
\text { these two (A and C) are right angles, if } \\
\text { they are connected together, then is this } \\
\text { side (AD) the same length as this side } \\
\text { (BC)?....., they can't be inclined! So, if } \\
\text { being inclined is impossible, and if these } \\
\text { two sides aren't drawn out, that means } \\
\text { these two sides must have the same length } \\
\text { (AD.BC). }\end{array}$ \\
\hline
\end{tabular}

(3) Refining and Justifying the Necessary Conditions for being a Rectangle: At the beginning, S1 deduced the property of parallel from the property of right angles. Even if interviewer constantly queried, S1 surely changed her solution into that it was satisfactory to only make sure that a pair of the opposite angles were right angles.

\begin{tabular}{|c|c|l|}
\hline 149 & $\mathrm{R}$ & $\begin{array}{l}\text { Then are you sure that it's a rectangle, } \\
\text { confirm }\end{array}$ \\
\hline 150 & $\mathrm{~S} 1$ & Uh. \\
\hline 151 & $\mathrm{R}$ & It won't be distorted \\
\hline 152 & $\mathrm{~S} 1$ & $\begin{array}{l}\text { I think it's the problem of how I measure, } \\
\text { if it's like this ( ), doesn't it have to } \\
\text { be a right angle? Then I draw it following } \\
\text { the line it shows, this side (left) won't be } \\
\text { inclined, then the side up here, of course } \\
\text { will be horizontal too. }\end{array}$ \\
\hline 153 & $\mathrm{R}$ & $\begin{array}{l}\text { Of course it won't be inclined, that's } \\
\text { right. }\end{array}$ \\
\hline 154 & $\mathrm{~S} 1$ & $\begin{array}{l}\text { Use the same method, we connect this } \\
\text { right up, I think it (right) won't be } \\
\text { inclined either, that is what I draw, I think } \\
\text { it won't be inclined. Because there are } \\
\text { two right angles, its...must be parallel } \\
\text { (up, down)... }\end{array}$ \\
\hline
\end{tabular}

(4) Cognitive Conflict: The researcher presented students with a counterexample to a conjecture that a quadrangle in which a pair of the opposite angles were right angles was a rectangle.

(5) Initially Proposed Properties of Squares:

\begin{tabular}{|l|l|l|}
\hline 195 & & (silence ) \\
\hline 196 & $\mathrm{R}$ & $\begin{array}{l}\text { Then ...ok... seems like you both want to } \\
\text { measure something, what is a rectangle } \\
\text { Anyway? What is a square? }\end{array}$ \\
\hline
\end{tabular}

After the researcher confronted subjects with the counterexample, they seemed astonished and were silent for seconds. Then, the researcher broached squares to them, and they respectively responded squares are that. $\mathrm{S} 2$ proposed that all angles are right angles and all sides are equal. S1 proposed that two pairs of opposite sides are parallel and all angles are right angles. All sides are equal.

(6) Refining and Justifying the Necessary Conditions for being a Square: S2 queried whether or not one should check that two pairs of opposite sides were parallel and supposed that it is satisfactory to measure four angles and four sides. It appeared that S1 had hesitated due to the influence of the counterexample of non-rectangles; however, she intuitively approved S2's argument. Through the argumentation, we explicitly observed that the subjects dismissed the idea of checking the property of parallel because parallel could be deduced from perpendicularity.

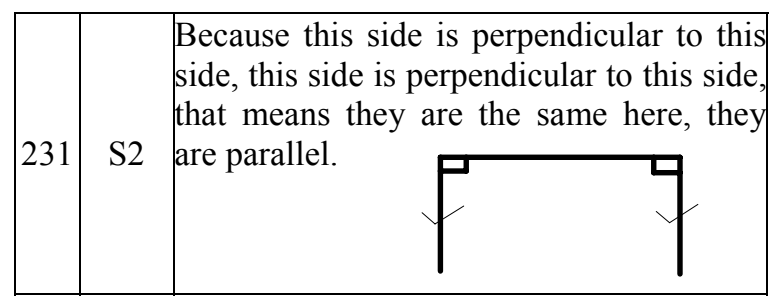

(7) Optimum Definitions of Rectangles: After confirming both of the subjects thought that four right angles and four equal sides were enough to determine a square, the researcher returned to asking rectangles. S1 had altered the misconception that it was enough to determine a rectangle only verifying that a pair of opposite angles were right angles and came up with four right angles from which S1 also inferred a square as a kind of a rectangle. However, S2 conjectured whether or not it could be done by measuring three angles, and then she proved the conjecture by visual reasoning.

\begin{tabular}{|c|c|c|}
\hline 492 & $\mathrm{R}$ & $\begin{array}{l}\text { So what is a rectangle, what is a } \\
\text { rectangle? }\end{array}$ \\
\hline 493 & $\mathrm{~S} 1$ & $\begin{array}{l}\text { Now the only thing we need to make sure is } \\
\text { four angles are right angles, ......, and I can } \\
\text { tell that if there are only two right angles, we } \\
\text { can't be sure that one side is longer, and one } \\
\text { side will be shorter, ......, you must have four } \\
\text { right angles,....., if we consider a square as a } \\
\text { kind of a rectangle, then it must be a rectangle. }\end{array}$ \\
\hline 494 & $\mathrm{R}$ & Uh, ok. \\
\hline 495 & $\mathrm{~S} 2$ & What if there are three angles \\
\hline 496 & $\mathrm{R}$ & $\begin{array}{l}\text { Ah ha, ok, ok, what if there are three } \\
\text { angles, very good, it's great, if only three } \\
\text { angles are right angles. }\end{array}$ \\
\hline 497 & $\mathrm{~S} 2$ & $\begin{array}{l}\text { (silence) } \\
\text { S2 draws }\end{array}$ \\
\hline
\end{tabular}

(8) Justifying the Necessary Conditions for being a Rectangle After the subjects confirmed that a quadrangle with three right angles implied the last angle of the quadrangle was a right angle, the researcher intervened to stimulate students to contemplate how to deduce that two pairs of opposite sides of a quadrangle are equal if three angles of the quadrangle were 
right angles.

\begin{tabular}{|l|c|l|}
\hline 543 & $\mathrm{R}$ & $\begin{array}{l}\text { Then when four angles are right angles, are the } \\
\text { opposite sides supposed to have the same } \\
\text { length? }\end{array}$ \\
\hline 544 & S1 S2 & Right. \\
\hline 545 & $\mathrm{R}$ & Then how do you know they are equal? \\
\hline 546 & S1 & $\begin{array}{l}\text { Because they are right angles, two sides } \\
\text { two sides of the right angles will be } \\
\text { parallel, it won't be stretching out, } \\
\text { because these two lines will always be cut } \\
\text { off like this, then because it a right angle } \\
\text { too, so it must be straight, and the } \\
\text { distance it's cut out will be the same } \\
\text { (means the upper and the lower sides have } \\
\text { the same length). }\end{array}$ \\
\hline 547 & $\mathrm{R}$ & $\begin{array}{l}\text { She is using the "cut", how about you, } \\
\text { Gia-Wen, what do you think? }\end{array}$ \\
\hline 548 & $\begin{array}{l}\text { That's because, I just said there's a right } \\
\text { angle here (angle A and angle B), this side } \\
\text { and this side will be the same (AD and } \\
\text { BC). }\end{array}$ \\
\hline B $\square$ \\
\hline
\end{tabular}

(9) Optimum of Definitions of Squares and Justifying the Necessary Conditions for being a Square: Up to now, the subjects had known that three right angles were enough to determine a rectangle. The researcher returned to asking how about squares. S1 answered that three angles were right angles, and four sides were equal. S2 answered that I was not sure and I still thought four angles were sufficient, which teachers always taught. The researcher encouraged S2 should trust herself, and S2 said that I thought three angles were enough. Following the thinking line of angles, the researcher intervened to stimulate students to draw an analogy between angles and sides, and the subjects conjectured that it might work to measure three sides. Next, The researcher continued intervening to stimulate students to ponder deeply over the possibility of only measuring two sides. S1 originally thought to measure a pair of opposite sides but refused the idea instantly. S2 followed to propose measuring two adjacent sides, and then both completed the task of verifying with different reasoning ways, which would be analyzed after sketching the defining activities.

\begin{tabular}{|c|c|l|}
\hline 612 & S1 & $\begin{array}{l}\text { Come on, but it doesn't mean that this } \\
\text { side will have the same length with this } \\
\text { side...( AB and BC ) }\end{array}$ \\
\hline 613 & $\mathrm{R}$ & Yeah... \\
\hline 614 & $\mathrm{~S} 1$ & Then how about three sides? \\
\hline 615 & $\mathrm{~S} 2$ & Then two sides ( AB and BC )? \\
\hline 616 & S1 & $\begin{array}{l}\text { Only these two sides? Then it can't even } \\
\text { be sure, hey, it will work, they are right } \\
\text { angles. }\end{array}$ \\
\hline
\end{tabular}

Let's diagram the above process of defining activities for picturing a clear image of the process. In each box of the diagram, students' activity is first outlined and the main modes of interventions during the activity are put in the bracket. The arrows accord with the procedure of defining activity. At the beginning, justifying after conjecturing was provoked by the interviewer, and afterward subjects automatically verified some relationships between properties.

Notations: *Rt: there is a right angle. Pl: a pair of opposite sides are parallel. El: a pair of opposite sides are equal-length. (o):opposite. Al: a pair of adjacent sides are equal-length. 4S: four sides are equal-length.

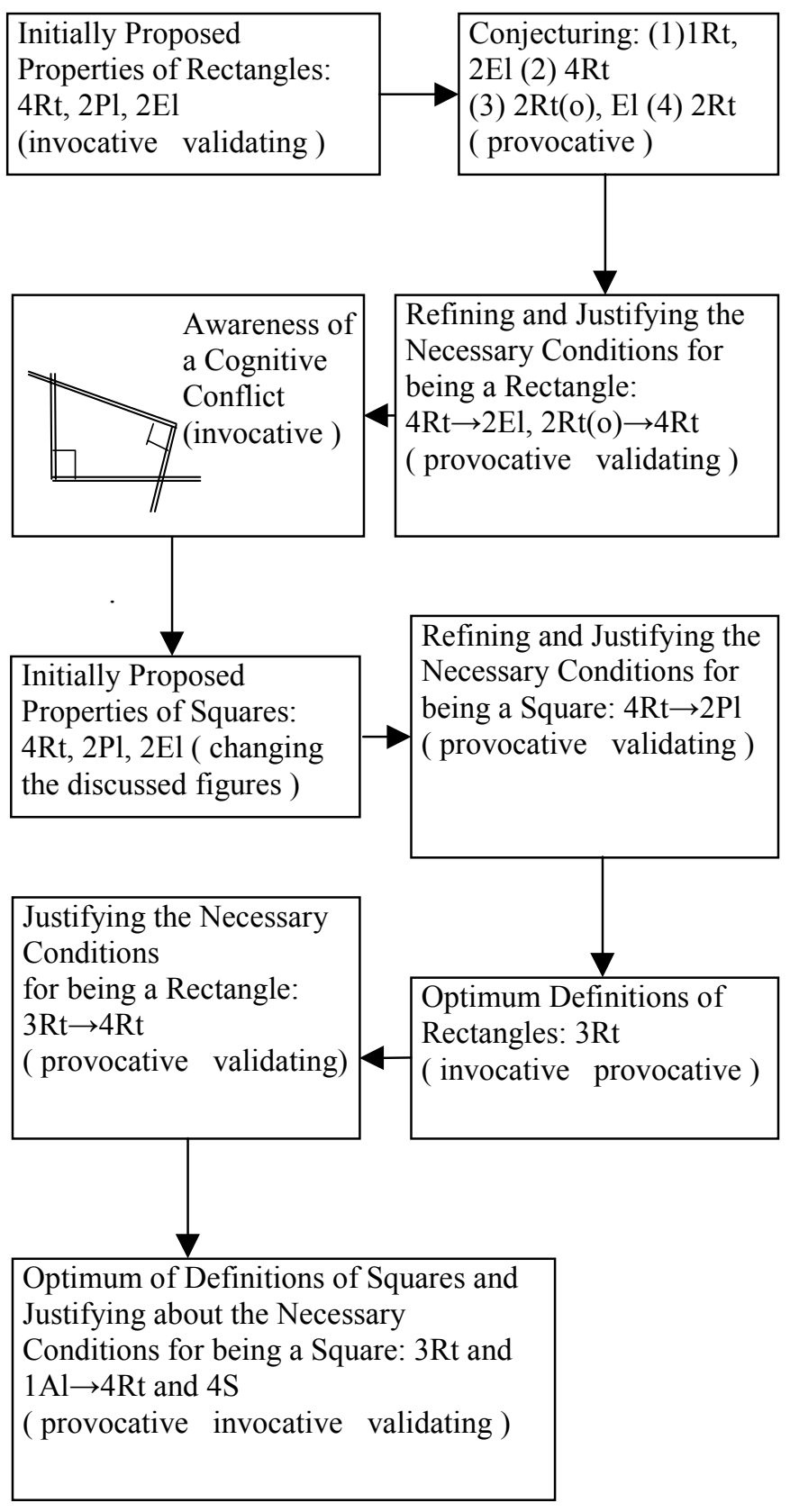




\section{Analysis}

In the case of the first interview, we would not analyze too much in the paper, but it still played a leading role. We would not have redesigned an innovative task which was more directly driven at the emergence of definitions if we had not found the genetic definition from subjects and not discovered vanish of the production of the first interview. In the following, we would analyze some argumentation segments of S1 and S2 with respect to the theoretical framework to describe what apprehensions of figures and theorems/concepts-in-action the subjects performed. In the end, the components of invariant character of a scheme (Vergnaud, 1998) for defining rectangles and squares were particularly elaborated to interpret what the subjects had experienced and how they conceptualized the defining activity.

\subsection{Apprehensions of Figures and Concepts/Theorems- in-action}

As a quasi-rectangle and the requirement of the less the better was confronted, S1 operated in mind two right angles opposite each other to compose a rectangle and posed a proposition that if a pair of opposite angles of a quadrangle are right angles, the quadrangle will be a rectangle. This coincided with a purely configural process as (modified sense of) operative apprehension and a natural discursive process (Duval, 1998). Why did S1 think it was plausible and fell so confident of this conjecture? Two explanations were made for this result

(1) S1 might apply a theorem-in-action that two pair of opposite sides are parallel respectively if a quadrangle has a pair of opposite right angles on the grounds of prototypical images of right angles. By reason of S1's theorem-in-action, she proposed the proposition, an idea from abduction. Because S1 surely manipulated two opposite right angles to compose a rectangle, we

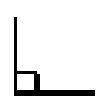

inferred she kept the theorem-in-action in mind (Fig. 5).

(2) S1 had believed that her proposition was correctly justified, she was not aware the possibility of any counterexample. Which kind of previous experiences or abilities are necessary for a student to aware the possibility of a counterexample? This seems an important educational issue for further study.

Theorem-in-action:Horizontal-verticalare orthogonal. Following S2's conjecture that measuring two adjacent sides in addition to three right angles would make sure of squares, S1 and S2 verified why two pairs of opposite

sides were equal by manipulating figures distinctly for their explanations. Imaging two horizontal lines in front of S1, she swung her two arms for vertically cutting and claimed that the middle part of the two parallel lines would hold the same length. By using a pencil denoting a line $\mathrm{AB}, \mathrm{S} 2$ moved the pencil along a horizontal line

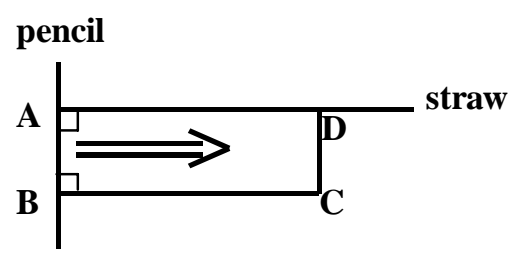

Fig. 6.

indicated by a straw and claimed that $\overline{A B}$ equals $\overline{C D}$ and $\overline{A D}$ equals $\overline{B C}$ (Fig. 6 ).

Apparently, S1's cutting method tends towards mental imaging, but S2's moving method tends towards processoriented where a theorem-in-action of isometric transformation was applied. Implicitly, that $\overline{A B}$ equals $\overline{C D}$ is reasoned by a line horizontally shifted, and that $\overline{A D}$ equals $\overline{B C}$ is reasoned that the locus formed by points from A to $\mathrm{D}$ and from $\mathrm{B}$ to $\mathrm{C}$ respectively. On the basis of this reasoning, two adjacent sides and three angles are sufficient to define a square.

The theorem-in-action of isometric transformation had occurred at S2's first glance of a quasi-rectangle when she proposed that measuring four sides and one angle could make sure a rectangle. We inferred that S2 implicitly transformed a parallelogram into a rectangle, which had obviously appeared in the first interview. The dynamic image from a parallelogram to a rectangle belonged

operative apprehension, and focusing on one angle belonged to perceptual

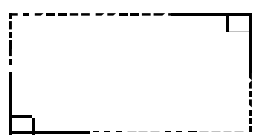

as Fig. 7 shows. apprehension. Both parts were dominated by a concept-in-action and a theorem-inaction respectively 
In contrast with $\mathrm{S} 1, \mathrm{~S} 2$ was rather reserved. We could not have found that S2's reasoning was productive if the researcher had not opportunely intervened in the argumentation activity. The researcher repeatedly encouraged S2 to express what she thought, and then S2 argued that the fourth angle was a right angle if three angles of a quadrangle were right angles. S2 constructed a rectangle according to a specific order identified as sequential apprehension, and she reasoned why the fourth must be a right angle via natural discursive process rather formal discursive process. Her natural discursive process can be interpreted as an application of the theorem-inaction as Fig. 8 shows. S2 intuitively thought her reasoning was plausible so we inferred that she might unconsciously hypothesize that if two lines are parallel, another line perpendicular to one of the two lines will be perpendicular to the other. In conclusion, the method of S2's argumentation towards geometrical figures seems full of dynamic processes.

\subsection{Invariant Organization of Defining Geometrical Figures}

Finally, we would reconstruct what was the invariant organization of developing definitions and propositions of geometrical figures in terms of four components of this

\begin{tabular}{|l|c|l|}
\hline 78 & S1 & $\begin{array}{l}\text { Yes, I think the right angles must be measured, } \\
\text { and I think two thousand is needed. }\end{array}$ \\
\hline $\mathbf{7 9}$ & S2 & How about this side and this side? \\
\hline 80 & S1 & $\begin{array}{l}\text { No, what I mean is if these two right } \\
\text { angles are fixed, these two must be right } \\
\text { angles (B.D), then won't the pool be built } \\
\text { together?............. }\end{array}$ \\
\hline
\end{tabular}

\begin{tabular}{|c|c|l|}
\hline 148 & S1 & $\begin{array}{l}\text { Then I draw it like this first, this, and this, } \\
\text { I'll draw like this first, ( )..... }\end{array}$ \\
\hline 149 & R & $\begin{array}{l}\text { Then are you sure that it's a rectangle, } \\
\text { confirm? }\end{array}$ \\
\hline
\end{tabular}

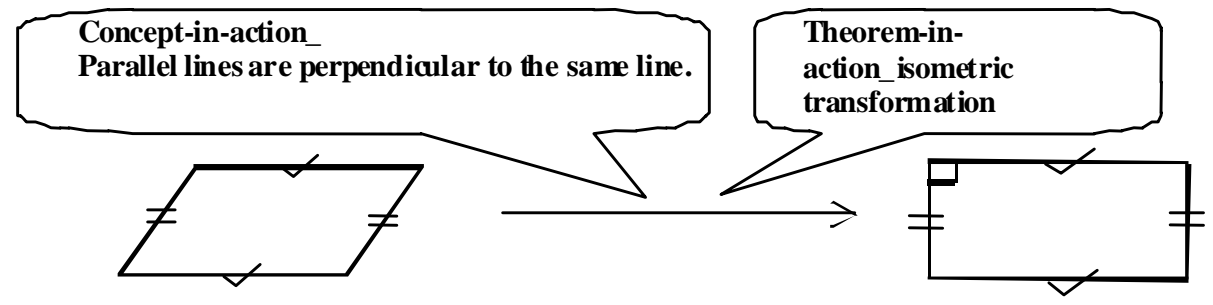

Fig. 7. S2's Perceptual, Operative and Discursive Apprehensions of Rectangles.

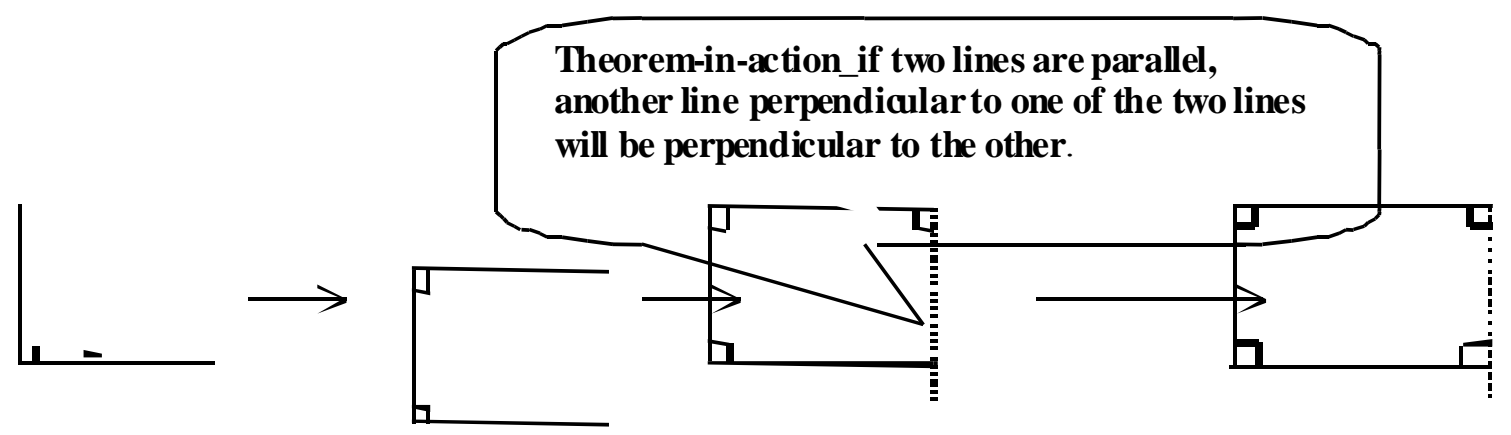

Fig. 8. S2's Sequential and Discursive Apprehensions of Rectangles.

organization in order to observe what is essential in the process of conceptualization.

(1) Goals, subgoals and expectations

The goal or expectation of the given task was to find the least payment for checking whether or not the swimming pool is rectangle, i.e., reinventing definitions of geometrical figures. The subgoals were set by conjecturing what must be measured or by verifying propositions and were initially produced by the interviewer but afterwards sometimes by subjects themselves. The interviewer had not to explicitly clarify subgoals but implicitly regulated subgoals.

\section{\begin{tabular}{l|l|l}
77 & S2 & This one is necessary.
\end{tabular}}

\begin{tabular}{|c|c|c|}
\hline 193 & $\mathrm{R}$ & Seems like that. \\
\hline 194 & S1 & $\begin{array}{l}\text { Considering the length.... ( talking to } \\
\text { oneself) }\end{array}$ \\
\hline 195 & & ( silence ) \\
\hline 196 & $\mathbf{R}$ & $\begin{array}{l}\text { Then ...ok...seems like you both want } \\
\text { to measure something, what is a } \\
\text { rectangle anyway? What is a square? }\end{array}$ \\
\hline
\end{tabular}

\begin{tabular}{|c|c|l|}
\hline 472 & $\mathbf{R}$ & $\begin{array}{l}\text { We still need to budget, you can't } \\
\text { measure them all. }\end{array}$ \\
\hline 473 & S1 & $\begin{array}{l}\text { That means we need to prove this is } \\
\text { correct. }\end{array}$ \\
\hline
\end{tabular}

(2) Rules of action

The second task functioned as part of generating argumentation schemes. Another indispensable part was driven by the interviewer. Giving counterexamples and hinting some analogy between measuring angles and measuring sides were included in the second interview to modify misconceived actions and to stimulate analogizing respectively, which did not occur in the first interview. Both the task and the intervention were 
planed to satisfy necessary conditions motivating students' actions.

\begin{tabular}{|l|c|l|}
\hline 592 & R & $\begin{array}{l}\text { Now let's take a look, what we just said was } \\
\text { four angles, it became three, then can four } \\
\text { equivalent sides shrink a little? NT\$100 } \\
\text { cheaper is NT\$100 cheaper, ha ha .... }\end{array}$ \\
\hline 593 & S1 & $\begin{array}{l}\text { Come on...don't look at me and laugh, } \\
\text { seems like NT\$100 is occupied by me, } \\
\ldots .\end{array}$ \\
\hline $\mathbf{5 9 4}$ & $\mathbf{R}$ & $\begin{array}{l}\text { Now the situation is three right angles } \\
\text { guarantee the right angle of the } \\
\text { fourth, right, we already know that, } \\
\text { then... }\end{array}$ \\
\hline $\mathbf{5 9 5}$ & $\mathbf{S 2}$ & \begin{tabular}{l} 
Three sides? \\
\hline
\end{tabular}
\end{tabular}

(3) Operational invariants

The concept of operational invariant (concepts-inaction and theorems-in-action) is the keystone that makes the connection between practice and theory (Vergnaud, 1998, p. 230 ). The definition of theorems-in-action is that propositions held to be true by the subject when he or she acts (1998, p. 229 ).

Examples of theorems-in-action and concepts-in-action with respect to the processes of the defining of rectangles and squares could refer to Fig. 5, 7 and 8 .

(4) Possibilities of inference

The subjects usually reasoned via natural language and manipulating figures; however, it did not mean they could not infer deductively. The prototypical geometrical figures and some implicit concepts/theorems-inaction may remain the biggest stumbling blocks to achieving the mathematical definitions of figures and to verifying deductively. On the other hand, there is no denying that manipulating figures would advantage subjects to transit from informal to formal argumentation; for instance, they conjectured some attributes by abduction while the researcher asked what the meaning of parallels is.
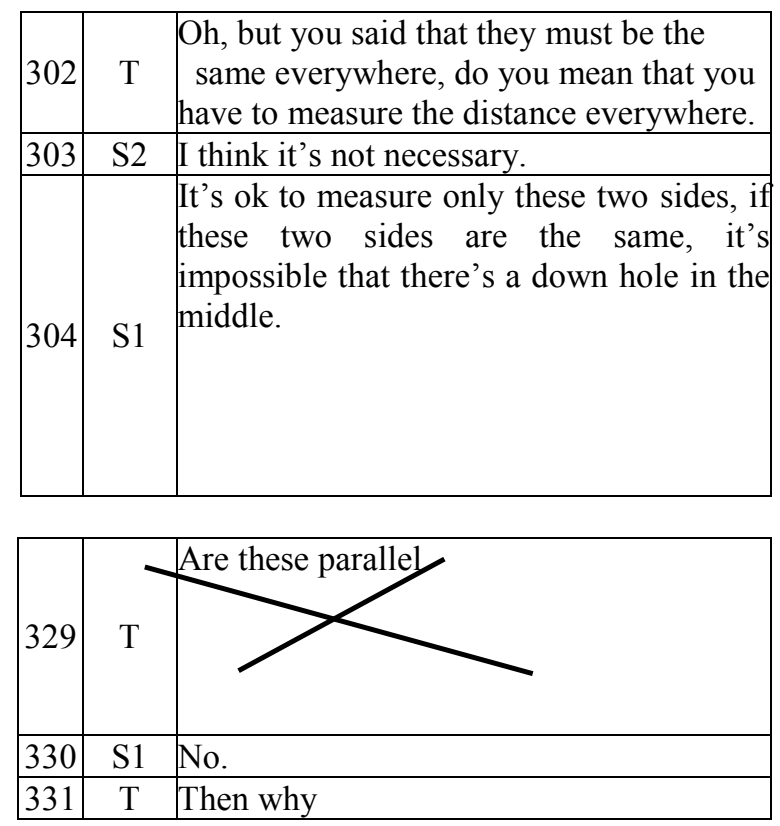

\begin{tabular}{|l|c|l|}
\hline 332 & S1 & They are perpendicular to each other. \\
\hline 333 & T & Nope. Which is being perpendicular \\
\hline 334 & S2 & They are intersecting. \\
\hline
\end{tabular}

\section{Conclusions and Implications \\ 6.1 The Characterization of Mental Images and the Process of Defining}

The concept images of figures in subjects' minds were first related to shapes and properties of figures, a kind of conjunctive concept, originating from prototypical images. On the basis of positions and properties as attributes of prototypical images, subjects recognize figures and construct their concepts/theorems-in-action implicitly thought to be assumptions or hypotheses by them. While manipulating subfigures (angles or sides), subjects intertwine unconscious concepts/theorems-in-action and perceived mental images of rectangles to verbally reason. On the other hand, rectangles were translated semantically into "long squares" in Chinese language, so the mental image of rectangles in S2's mind was that one side needed to be longer than adjacent sides, but S1 was not influenced by "long squares" and identified squares as a kind of rectangles according to the attribute of determining rectangles, right angles. The result exhibited that subjects could extract the structure of a mathematical concept from mental images by informal reasoning in practical activities, which offer another strategy for understanding definition except giving meaning to a definition and extracting meaning from the definition (Tall et al., 2001). Furthermore, we would predict a procedure of recurring the development from mental images to mathematical definitions. The process of defining familiar figures is led off with analyzing properties of figures, conjecturing necessary attributes of given figures and relationships between properties is next. Verifying or refuting these conjectures is provoked under social interaction. Last but not least, we found students were not skillful to write down their proving. If we just analyzed subjects' proof written in paper, we would have lost some productive information such as how subjects manipulate subfigures and the motive power of supporting argumentation.

\subsection{The Cognitive Architecture of Defining Geometrical Figures}

The modified architecture of defining geometrical figures with respect to 7 th graders is illustrated with Fig. 9. The intentional division and the automatic division are considered as cultural tools, important means of communication, and as individual mind, both consciousness and unconsciousness, respectively. Subjects interweave cultural tools and their mind to conceptualize the defining activity. Conceptualization is substituted for internalization because conceptualization can be regarded as conceptual fields with scheme (Vergnaud, 1990; 1998), and conceptualization includes the process of appropriation, a dialectic of internalization and interiorization (Lewin, 1991). Besides, we suppose and emphasize that encapsulation (Dubinsky, 1991) included in conceptualization may evolve not only into real understanding but also misunderstanding, e.g. incorrect theorems/concepts-in-action. 
While conceptualizing the defining of geometrical figures, what intentional and automatic working takes up subjects' thinking and how do subjects coordinate different registers? In the above, The subjects utilize two language. S1 inclined to verbally perform, which made us effortless for reconstructing her reasoning. In contrast, S2 needed much encouragement to verbalize her thought. According to her reasoning by induction or abduction, we
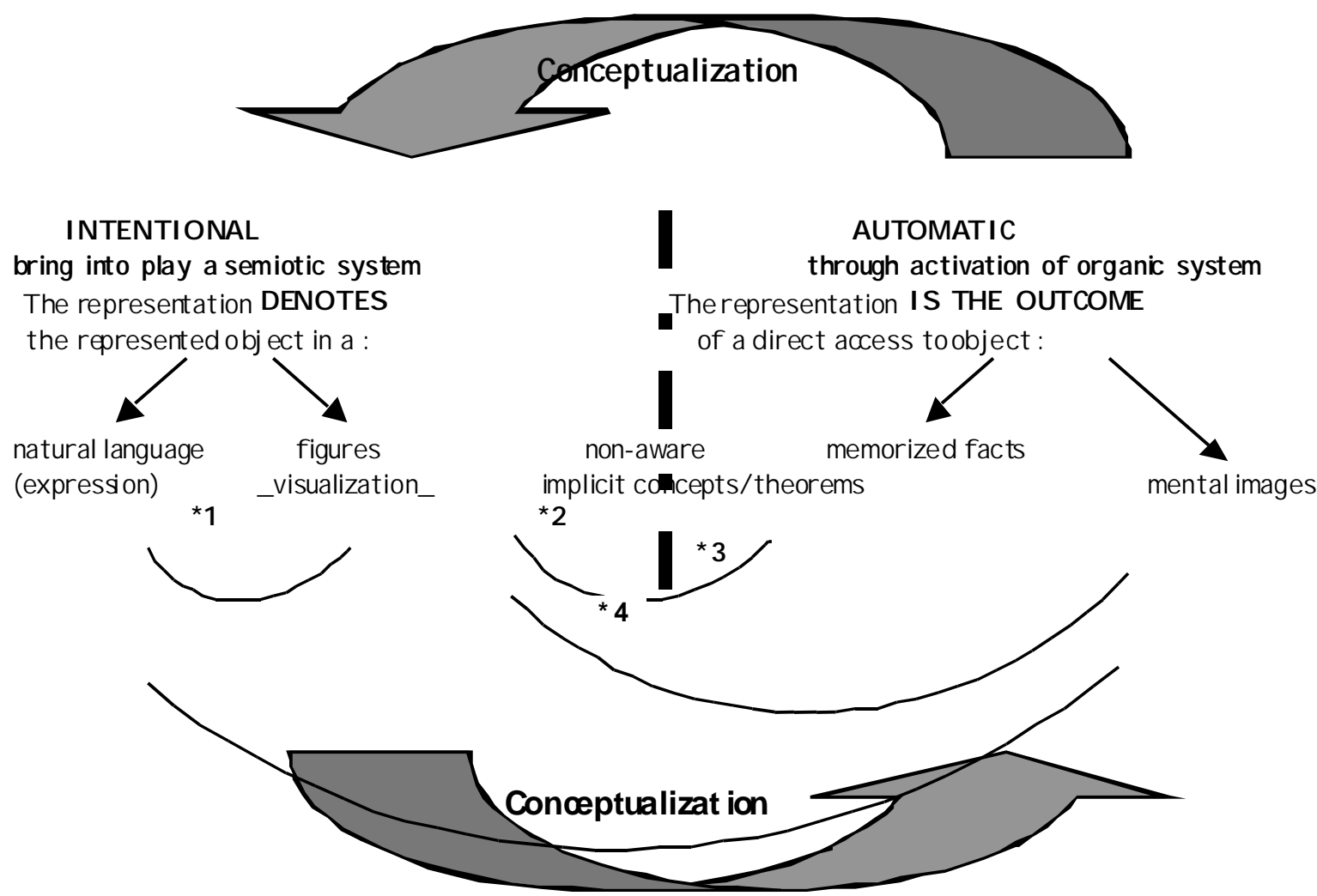

Fig. 9. Cognitive architecture of defining rectangles.

registers, natural language and geometrical figures in the intentional system to interiorize the defining underlying imitation (memorized facts), mental images and implicit concepts/theorems in the automatic system and modified two registers in the automatic system to internalize the defining activity merging their own reasoning and social interaction. They manipulate subfigures or figures to reflect their mental images $(* 3)$ and to express in natural language $(* 1)$. It seems no obstacles of coordination between natural language, figures and mental images because the subjects accommodate their language firstly to mental images not to logic. Despite coordination, disequilibrium among registers sometimes occurs. The struggle between the memorized fact that the teacher used to say there are four right angles in a square and S2's immediate experience $(* 1, * 3, * 4)$ makes her abandon the conclusion that three right angles are sufficient to identify a quadrangle as a rectangle and return to the memorized fact. As for implicit concepts/theorems (*2), we have specified how concepts/theorems-in-action influenced subjects' visualization.

Why are there no connections between implicit concepts/theorems and natural language or memorized facts/images? It does not imply no inner interaction in automatic system, and we just want to emphasize that the inner interaction mainly originates from subjects' visualization and then being expressed by natural appraised that she conjectured and manipulated figures more creatively.

In brief, the characteristic of informal reasoning in geometry is carrying out imaginary processes via manipulating subfigures like manipulable symbols in algebra and merging implicit concepts/theorems and perceptual images of figures to conceptualize the definition of rectangles and to coordinate visualization and natural language.

\subsection{The Successful Transition to the Definition of Rectangles}

Two factors are a great contribution to the successful transition from concept images to concept definitions. One is the social setting, the interviewer's intervention, and the other is the practical setting, the swimming pool task. The two factors dominate the invariant organization of defining geometrical figures as analyzed in section 5.2. A condition that the payment is the less the better well set a meaningful goal for the subjects so they automatically contemplated the possibility of reducing attributes of figures. Although the second task is recommended as a teaching material to bridge informal and formal reasoning, it still involves one drawback of eliminating equivalent definitions caused by the condition that the payment is the less the better; nevertheless, the drawback can be get rid of. If students do not come up any other 
equivalent definition, teachers can offer other equivalent definitions for stimulating evaluation of different definitions.

On the other hand, the interviewer played a lubricative and intervening mediator in both processes from intentional to automatic and vice versa. He inferred when and how to give conflicting figures, to provoke the subjects' reflection on their actions and to invoke a shift in familiar topics. Through recapping the result, S1 said that "I'll never forget it for the rest of my life in the end". Two months later, her teacher asked her which elements determine rectangles, and she plainly recalled three right angles. Hence, besides an innovative task for the emergence of defining is designed, some prolific principles of teaching should be extracted and organized for teachers with the goal of the successful transition to mathematical definitions. When one offer the second task in classes, he or she may have to notice that:

(1) First of all, one may conceptualize what students' schemes are according to Vergnaud's definition of scheme.

(2) When students have been stumbled by misdiagnosing the validity of reasoning and felt confident, one may push them forward to reflect what they have done, what kind of counterexamples could be invented or what naïve ideas could be generated via making their concepts-in-action or theorems-in-action explicit, through which students may intend testing their mis-hypotheses.

(3) If students have no ideas of conjecturing, one may inform their prior experience by analogy to allow them to analogize.

\subsection{What direction for the future}

We have showed that students could reason via manipulating their mental images to derive definitions. We will try to design assessment tools for the purpose of how 7 th-8th graders evaluate the validity of reasoning and what percentage of 7 th- 8 th graders own the theoremin-action: if a quadrangle has a pair of opposite right angles, then two pair of opposite sides are parallel respectively, both of which affect progress towards formal reasoning.

\section{Acknowledgements}

This work was funded by the National Science Council of Taiwan ( NSC 89-2511-S-003-103 ). We are grateful to the members of the research team, Tam, H.P., Yu Wu, J.Y., Chen, C.Y., Chen, E.R., Lin, C.Z., Hao, S.C, Lin, J.H., Lee, E.F. and Liang, H.J., who have made their contributions on analyzing the transcriptions and developing some ideas of this paper. Views and opinions are those of authors and not necessarily those of NSC. Particularly we thank R. Duval for these valuable comments on some analysis of this paper.

\section{References}

Balacheff, N. (1990). A study of students' proving processes at junior high school level. In Wirszup, I. \& Streit, R. (Eds.), Developments in school mathematics education around the world, 284-297. Chicago: NCTM.

Cifarelli, V. V. (2000). Mental projections in mathematical problem solving: Abductive inference and schemes of action in the evolution of mathematical knowledge. PME24, 2, 185223.

Davis, P. J. (1993). Visual Theorems. Educational Studies in Mathematics, 24, 333-344.

Dubinsky, E. (1991). Reflective abstraction in advanced mathematical thinking. In D. O. Tall (ed.), Advanced mathematical thinking. Dordrecht, Netherlands: Kluwer.

Duval, R. (1995). Geometrical pictures: Kinds of representation and specific processings. In R. Suttherland \& J. Mason (Eds.), Exploiting mental imagery with computers in mathematics education, 142-157. Berlin: Springer.

Duval, R. (1998). Geometry from a cognitive point a view. In C.Mammana \& V.Villani (Eds.), perspectives on the teaching of geometry for 21 st century, 37-52. Dordrecht: Kluwer.

Duval, R. (2000). Basic issues for research in mathematics education. PME24, 1, 55-69.

Evans, J. St. B. T., Newstead, S. E. \& Byrne, R. M. J. (1993). Human reasoning: The psychology of deduction. UK: Lawrence Erlbaum Associates Ltd.

Fischbein, E. (1993). The theory of figural concepts. Educational Studies in Mathematics, 24, 139-162.

Fischbein, E. (1996). The psychological nature of concepts. In H. Mansfield et al. (Eds.), Mathematics for Tomorrow's Young Children. Netherlands: Kluwer.

Freudenthal, H. (1973). Mathematics as an educational task. Dordrecht: Reidel.

Hardad, K., Gallou-Dumiel, E. \& Nohda, N. (2000). The role of figures in geometrical proof : problem solving-students' cognitions of geometrical figures in France and Japan. PME24, 3, 25-32.

Hermina J.M. Tabachneck-Schijf and Simon, H.A. (1996). Alternative representations of instructional material. In D. Peterson (ed.), Forms of representation. UK: Intellect Books Ltd.

Holes, C.\& Healy, L. (1999). Lining informal argumentation with formal proof through computer-integrated teaching experiments. In O. Zaslavsky (Ed.), PME23, 3, 105-112.

Holland, J. H. et al. (1986). Induction: Processes of inferences, learning, and discovery. Cambridge, Mass.: MIT Press.

Inhelder, B., Sinclair, H. \& Bovet, M. (1974). Learning and the development of cognition. Cambridge, Mass.: Harvard University Press.

Janvier, C. (1987). Translation process in mathematics education. Problems Representation in the Teaching and Learning of Mathematics, 27-32.

Kieren, T.E. \& Pirie, S.E.B. (1992). The answer determines the question: Interventions and the growth of mathematical understanding. PME16, 2, 1-8.

Lakatos, I. (1977). Proofs and refutations. Cambridge: Cambridge University Press.

Mariotti, M. A. \& Fischbein, E. (1997). Defining in classroom activities. Educational Studies in Mathematics, 34, 219-248.

Moore, R. (1994). Making the transition to formal proof. Educational Studies in Mathematics, 27, 249-266.

Tall, D. et al. (2001). Symbols and bifurcation between procedural and conceptual thinking. Canadian Journal of Science, Mathematics and Technology Education, 1, 81-104.

Turston, W.P. (1994). On proof and progress in mathematics. Bulletin of the American Mathematical Society, 30, 161-177.

Vergnaud, G. (1990). Epistemology and psychology of mathematics education. In Mathematisc and Cognition: A research synthesis by the International Group for the Psychology of Mathematics Education, Cambridge, MA: Cambridge University Press.

Vergnaud, G. (1998). Towards a cognitive theory of practice. In A. Sierpinska \& J. Kilpartick (Eds.), Mathematics education as a research domain : A search for identity, 227-240. Dordrecht, Netherlands: Kluwer Academic Publishers. 
Vinner, S. (1991). The role of definitions in teaching and learning of mathematics. In D. Tall (Ed.), Advanced mathematical thinking, 65-79. Dordrecht, Netherlands: Kluwer Academic Publishers.

\author{
Authors: \\ Fou-Lai Lin, Department of Mathematics, National \\ Taiwan Normal University, 88, Sec. 4, Ting-Chou Road, \\ Taipei, Taiwan. \\ E-mail: mailto:linfl@math.ntnu.edu.tw \\ Kai-Lin Yang, Department of Mathematics, National \\ Taiwan Normal University, 88, Sec. 4, Ting-Chou Road, \\ Taipei, Taiwan. \\ E-mail: mailto:kailin@math.ntnu.edu.tw
}

